\title{
Magnesium pemoline: Effects on dril performance
}

\author{
YASUKO FILBY AND LUCILLE FRANK \\ CREEDMOOR INSTITUTE FOR PSYCHOBIOLOGIC STUDIES
}

Magnesium pemoline ( $\mathrm{MgPe}$ ) has been found to facilitate avoidance performance. Several workers have suggested that this facilitation is due to drug-induced increases in motor activity and sustained responsivity to the warning stimulus and not to an enhancement of central associative mechanisms. We compared the performance of rats given $5,10,20,40 \mathrm{mg} / \mathrm{kg}$ $\mathrm{MgPe}$ or a control solution in a drl situation where increases in motor activity or stimulus responsivity would not necessarily facilitate performance whereas an improvement in central associative processes would. Results showed that $\mathrm{MgPe}$ did not facilitate, but at higher doses impaired, drl performance.

Recent studies have confirmed Plotnikoff's (1966) report that magnesium pemoline (MgPe) facilitates avoidance performance (Beach \& Kimble, 1967; Frey \& Polidora, 1967; Filby, Szara, \& Salzman, 1967). However, the mechanism by which avoidance performance is enhanced remains unclear. Several workers have suggested that this facilitation is due to factors which affect performance but not learning. Beach \& Kimble (1967) suggest that avoidance facilitation occurs through drug-induced increases in motor activity and sustained responsivity to external stimuli (such as the warning signal in the avoidance situation) rather than being due to enhancement in learning ability. Frey \& Polidora (1967) suggest that the drug may facilitate avoidance performance by decreasing freezing behavior and increasing motor activity rather than by improving "some general learning mechanism (through the drug acting upon) the biochemical system which synthesizes nucleic acids." 1

The present study tested the effects of magnesium pemoline in a drl (differential reinforcement of low rate) situation where these observed drug effects would not result in spuriously enhancing performance. That is, (1) food reward was the incentive, rather than shock avoidance; (2) reinforcement was contingent on a low rate of responding (drl $20 \mathrm{sec}$ ); and (3) no external stimuli signaled the availability of reward. Thus, a drug-induced increase in spontaneous motor activity or in stimulus responsivity, or a drug-induced decrease in freezing behavior, would not result in facilitating acquisition of this drl performance. However, if the drug improved central associative mechanisms, as suggested by Plotnikoff, drug animals should show superior learning to controls.

Subjects

Thirty male, experimentally naive, Osborn-Mendel rats, 120 days old at the start of the experiment, were randomly assigned to five groups: $5,10,20$, and $40 \mathrm{mg} / \mathrm{kg} \mathrm{MgPe}$ groups, and a control. The control injection was a $.3 \%$ tragacanth solution which was the suspension used for the MgPe injections.

\section{Apparatus}

Two identical standard operant conditioning boxes, each equipped with a bar, a pellet-food dispenser (dispensing $45 \mathrm{mg}$ pellets) and food hopper, a water bottle, a dim house light, and background white noise were used. Programming and recording apparatus were housed in an adjacent room.

\section{Procedure}

Each $\mathrm{S}$ was run individually in $1 \mathrm{~h}$ sessions daily (omitting weekends). The first two sessions habituated the $S$ to the experimental box: 50 food pellets were present in the hopper; no bar was present. On the third and fourth days, food was dispensed automatically at variable intervals averaging $1-1 / 2 \mathrm{~min}$ apart to acclimatize the rat to the sound of the food dispenser; no bar was present. On the fifth and subsequent days, the bar was present. Each animal was now required to bar press for food. Each bar press yielded a pellet of food. Bar press training continued until the $S$ earned 100 food pellets in a single session. All but two Ss learned to bar press within three sessions of bar press training; the two ss which failed to learn within three sessions were discarded. Control and drug injections were not begun until the end of bar press training. The day following the last bar press training session, the $S$ was given the first injection of its designated drug. Each $S$ received an IP injection $30 \mathrm{~min}$ before each session for the next 15 sessions. At the beginning of this first session following the last bar press training session, the $\mathrm{S}$ continued to receive a reinforcement ( $r f t$ ) for each bar press for the first 10 bar presses, then was switched to a schedule (which continued in effect for the next 15 sessions) where an $\mathrm{rft}$ could be earned by a bar press only if $20 \mathrm{sec}$ or more had elapsed since the last bar press. Any bar press which occurred less than $20 \mathrm{sec}$ since the last response reset the $\mathrm{rft}$ timer, and the $S$ was required to wait another $20 \mathrm{sec}$ to obtain an rft by bar pressing.

\section{Resulis}

Three measures were used as indices of performance: (1) No. of $\mathrm{rft}^{\prime}$ s obtained per session, (2) median inter-response times (IRTs) per session, and (3) No. of responses per session. Separate analyses of variance over the 15 sessions on these three measures all showed significant differences, either at the .05 or .01 levels, due to both drug treatments and to sessions. The control group and the lowest dose group $(5 \mathrm{mg} / \mathrm{kg}$ ) performed better than the 10,20 , and $40 \mathrm{mg} / \mathrm{kg}$ groups. The $5 \mathrm{mg} / \mathrm{kg}$ group did not differ significantly from the control group. Figures 1 (showing No. of rft's obtained per session by each group over the 15 sessions) and 2 (showing the average IRTs per session per group over the 15 sessions) 


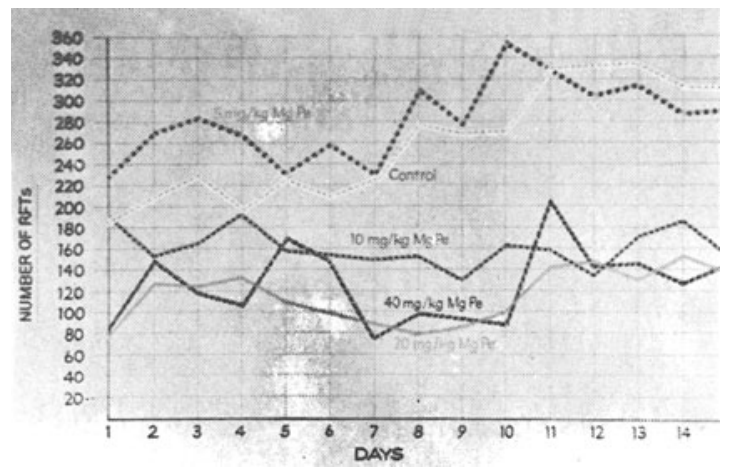

Fig. 1. No. of rft's obtained by each group during the 15 sessions of drl training.

both show that the inferior performance of the higher dose groups was apparent from Session 1 , and continued through Session 15 (although there was no significant difference between the groups prior to being placed on the drl schedule). On the measure of No. of responses, the higher dose groups showed higher responding; all groups decreased responding over the 15 sessions. There were no significant interactions between drug treatment and sessions on any of the three measures.

\section{Discussion}

$\mathrm{MgPe}$ at a low dose (5 $\mathrm{mg} / \mathrm{kg})$ did not facilitate, but at the higher doses $(10,20$, and $40 \mathrm{mg} / \mathrm{kg}) \mathrm{im}$ paired the ability of hungry rats to obtain food in a drl situation. This impairment in drl performance is similar to that reported for other CNS-stimulants, such as D-amphetamine (Weiss \& Laties, 1964).

However, all three measures showed significant sessions effect, indicating that performance of the groups changed significantly during the 15 sessions. Figure 2 shows that average IRTs increased for all groups over the 15 sessions (all groups showed significant $t_{\text {diff }}$ values when Session 1 was compared with Session 15). No. of rft's (Fig. 1) showed a similar, but less marked, trend while No. of responses per session systematically decreased over sessions for all groups. Thus, although MgPe did not facilitate drl performance, it also did not prevent learning in this sense from occurring.

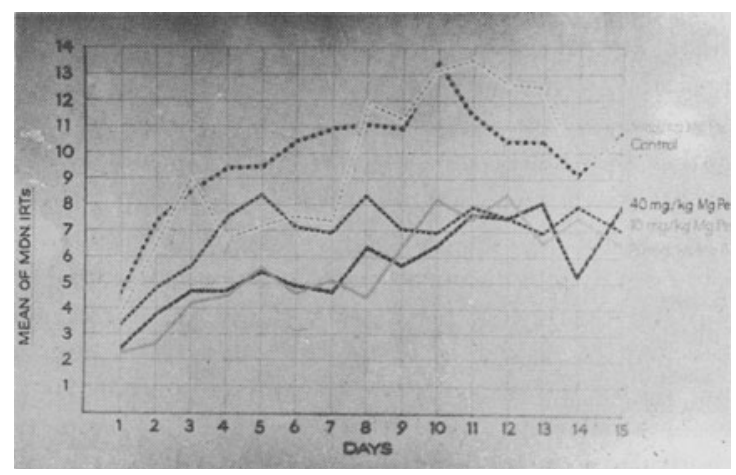

Fig. 2. Average IRT s of each group during the 15 sessions of drl training.
However, the lack of a significant interaction effect between drug treatment and sessions indicated that this improvement in performance did not differ between groups. That is, although the higher dose groups showed poorer performance at the outset, they improved their performance in a parallel manner to the control and low dose $\mathrm{MgPe}$ groups. Improvement in performance over sessions was not facilitated for any group,

In a separate study (Gianutsos, Gianutsos, \& Filby). groups of rats were given $5,10,20,40 \mathrm{mg} / \mathrm{kg} \mathrm{MgPe}$ or control (.3\% tragacanth) injections one day per week over a six week period, and their activity levels and food intakes measured during the subsequent $22 \mathrm{~h}$ period. No difference in food intake was found between the groups. Generalizing from these findings, we assume that there was no anorexic effect due to the drug, and thus differences in food motivation could not account for the lack of performance facilitation found in the present study. ${ }^{2}$

The lack of performance facilitation obtained in the drl situation contrasts with performance facilitation found in avoidance situations. If $\mathrm{MgPe}$ enhances central associative mechanisms, we would expect facilitation in both situations. If, however, the drug action is primarily on performance factors, e.g., increasing motor activity and stimulus responsivity and decreasing freezing behavior, we would expect facilitation in a signaled shock-avoidance situation but not in a food-motivated drl situation where there is no external warning signal, and where a low bar pressing output is favored. Thus, these results support the view that $\mathrm{MgPe}$ affects performance but not learning factors.

\section{References}

BEACH, G., \& KIMBLE, D. P. Activity and responsivity in rats after magnesium pemoline injections. Science, 1967, 155, 698-701.

FILBY, YASUKO, SZARA, S., \& SALZMAN, B. Magnesium pemoline: effect on acquisition and retention of discriminated avoidance behavior. Psychon. Sci., 1967, 9, 131-132.

FREY, P. W., \& POLIDORA, V. J. Magnesium pemoline: effect on avoidance conditioning in rats. Science, 1967, 155, 1281-1282.

GIANUTSOS, J., GIANUTSOS, ROSAMUND, \& FILBY, YASUKO. Magnesium pemoline: effects on spontaneous activity level, stimulus responsivity and food intake over a 22 -hour period, in preparation.

GLASKY, A. J., \& SIMON, L. N. Magnesium pemoline: enhancement of brain RNA polymerases. Science, 1966, 151, 702-703.

MORRIS, N. R., AGHAJANIAN, G. K., \& BLOOM, F. E. Magnesium pemoline: failure to affect in vivo synthesis of brain RNA. Science, 1967, 155, 1125-1126.

PLOTNIKOFF, N. Magnesium pemoline: enhancement of learning and memory of a conditioned avoidance response. Science, 1966, 151, 703-704.

STEIN, H. H., \& YELLIN, T. O. Pemoline and magnesium hydroxide: lack of effect on RNA and protein synthesis. Science, 1967, 157, 96-97.

WEISS, B., \& LATIES, V. G. Drug effects on the temporal patterning of behavior. Federation Proc., 1964, 23, 801-807.

Notes

1. Recent reports (Morris et al, 1967; Stein \& Yellin, 1967) which have failed to replicate the earlier finding (Glasky \& Simon, 1966) that MgPe increases RNA synthesis make this hypothesized mechanism of action even more unlikely.

2. Similarly, no developing tolerance to the drug was detected. There was no significant difference from week to week in activity levels of these drug-treated animals. 